\title{
Prólogo \\ Reformas agrarias en América Latina y Chile: lecciones aprendidas sobre la controversia de la propiedad de la tierra
}

\author{
Daniella Gac Jiménez
}

CEDER - Universidad de Los Lagos, Santiago, Chile Email: daniella.gac@ulagos.cl

\section{Daniel Flores Cáceres}

CEDER - Universidad de Los Lagos, Santiago, Chile

Email: danielflorescaceres@gmail.com

\section{Marcel ThezáManríquez \\ CEDER - Universidad de Los Lagos, Santiago, Chile Email: marcel.theza@ulagos.cl}

En el contexto de la conmemoración del $50^{\circ}$ aniversario de la promulgación de la Ley $\mathrm{N}^{\mathrm{o}} 16.640$ sobre la reforma agraria, dictada en julio de 1967, un conjunto de instituciones académicas, gubernamentales y de la sociedad civil, han impulsado actividades para contribuir al rescate y fortalecimiento de la memoria histórica sobre este proceso de modernización, tanto productivo como social del país y América Latina, que impactó de diversas maneras los espacios rurales en donde se llevó a cabo.

Esta fecha ha sido una oportunidad para impulsar un enriquecedor debate acerca de los fundamentos desde donde se erguía esta reforma, así como también los efectosde ésta en los territorios agrarios, mirados a 50 años de su implementación. Lo anteriorpone de manifiesto no sólo el impacto histórico que tuvo este proceso, sino también la importancia de volver la mirada hacia los territorios agrarios para revisar las actuales problemáticas producto del proceso de modernización de los campos de América Latina e identificar la relevancia que tienen hoy los preceptos que ésta impulsó tanto en lo que respecta al orden productivo como a las transformaciones sociales donde ésta se implementó.

En lo que concierne a América Latina, es posible advertiruna vasta experiencia de modelos de reformas, de naturalezas políticas sociales y económicas muy variadas, tales como la reforma agraria mexicana, la reforma boliviana, originadas por Revoluciones (la Revolución Mexicana de 1910 
y la Revolución Boliviana de 1952), como las reformas impulsadas como consecuencia de un modelo de concentración de propiedad, como las impulsadas en Chile, Perú y Nicaragua, entre otras. Sin embargo, a pesar de los disimiles contextos, dentro de las transformaciones que tuvieron lugar en los campos, es posible identificar problemáticas centrales donde se posaron los esfuerzos para llevar a cabo su implementación:

En primer lugar, las problemáticas de tipo simbólico culturales, donde la posesión o el dominio de la tierra estaban asociados a una clara díada de riqueza y de poder, con efectos muy claros en la arquitectura social y política desigual de los países. Lo cual se manifiesta, hasta muy entrado el siglo XX en las zonas rurales, con el predominio del sistema latifundista con una "cultura patronal” que le acompaña - asociado a la figura del inquilino.Razón por la cual la apuesta de la reforma agraria fue darle cabida al campesinado como un actor relevante de la sociedad moderna, adquiriendo un papel central los movimientos sociales de la época.

En segundo lugar, el problema de la matriz productiva, debido a que parte significativa de las tierras de América Latina se mantenían ociosas o dedicadas a actividades como la ganadería extensiva o al mono cultivo tradicional. Situación que ha sido asociada a las escasas condiciones del sistema hacendal para impulsar un proceso de modernización del sistema productivo agrario.

En tercer lugar, un problema de tipo social, dada la magnitud de la población rural existente en América Latina a mediados del siglo XX, representando, en muchos casos, más del 50 por ciento de la población total. Situación que se conjugaba con problemas de analfabetismo y altas tasas de mortalidad, que, junto a los problemas de acceso a servicios básicos y condiciones de habitabilidad dignas, constituían un contexto de marginación social muy elocuente.

Desde la perspectiva histórica, fue la revolución mexicana la que en los inicios del siglo XX impulsó las primeras reformas agrarias en esta parte del continente (1917). Para el resto de América Latina, la discusión se instala con fuerza desde los años '30 en adelante, con algunas iniciativas y acciones reformistas que se sucedieron en las décadas del '40y del '50; sin embargo, fue particularmente a partir de los años '60 que diversas reformas agrarias se promulgaron en la Región.

Para estos efectos, un antecedente relevante fue el impulso de la Conferencia Interamericana de Punta del Este, y el apoyo político y económico prestado por el gobierno de Estados Unidos en el marco de la Alianza por el progreso. Las reformas agrarias eran, desde esta perspectiva, vistas como iniciativas destinadas a bajar la presión de un movimiento popular concebido como una amenaza bajo el entendido de estar ya plenamente instalados en una lógica de guerra fría. Por ello, parte importante de las reformas agrarias iniciadas en los años '60privilegiaron políticas más bien de compromiso, cuyo objetivo era precisamente disminuir las presiones y 
conflictos rurales, sin plantear una verdadera modificación estructural, en lo que respecta a lo social, pero de gran impacto y relevancia en lo que concierne al impulso económico productivo capitalista que se quería promover por medio de estas reformas.

En elcaso chileno, la reforma agraria adquirió, fundamentalmente en el período de la Unidad Popular, un carácter de cambio de orden estructural. En rigor, la política de la reforma agraria buscó en esos años no sólo resolver el problema de la concentración y redistribución de las tierras, sino, a la vez, modificar las relaciones de poder en el mundo rural. Por ello su propósito político fue claramente impulsar activamente la participación de los campesinos en el manejo de los predios expropiados, buscando igualmente convertir al sector reformado en un pilar básico de la producción agraria. En este contexto la idea de reforma agraria siempre fue vista por los gobiernos que impulsaron estas reformas (Eduardo Frei Montalva, 1964 - 1970); Salvador Allende, 1970 - 1973), como un objetivo político clave, dada la convicción de que ella conduciría a una sociedad rural más justa y a un desarrollo económico para el sector agrícola campesino.

Con la llegada de la dictadura militar (septiembre de 1973), fue evidente la ruptura del proceso de redistribución de tierras impulsado por los presidentes Frei y Allende. Lo anterior no siendo un proceso inmediato dada las complejidades en el tratamiento de los efectos legales y prácticos de la reforma, terminó clausurando este proceso en el año 1978 a través del decreto de ley $\mathrm{N}^{\circ}$ 2.247, lo cual implicó la derogación de las causales de expropiación que aún persistían en la legislación chilena y que derivaban en la reforma constitucional de 1967 sobre derecho de propiedad.

A partir de los años '80, gran parte de los países de América Latina adoptaron nuevas políticas económicas, particularmente en relación a la díada mercado -recursos naturales. A través de este tipo de políticas se propició una disminución radical de la intervención del Estado, la eliminación de los subsidios y protecciones a la producción interna, sumado a una adhesión completa a las reglas del libre mercado. Este escenario tuvo efectos muy nítidos en la actual configuración de la ruralidad.

De esta forma, los estados fueron ejerciendo un "sesgo antirural" a través de políticas que han privilegiado zonas urbanas y prácticas agroindustriales industriales de exportación. De igual forma, han sido debilitadas las agencias antes dedicadas a la inversión y el desarrollo agrícola no industrial, lo que ha provocado un impacto muy negativo para los pequeños productores que no están necesariamente vinculados a la actividad del "boom productivo exportador" y del modelo alimentario global impulsado por los gobiernos a inicios delos años '90.

Hoy en día el problema de la tierra parece no estar resuelto. Según datos de la Organización de las Naciones Unidas para la Alimentación y la Agricultura - FAO, la pobreza persiste en las zonas rurales, donde, en rigor, vive el $75 \%$ de los pobres del mundo. En Chile,a pesar de que la pobreza 
rural se ha reducido a un tercio desde los años '80, el habitar en zonas rurales “te permite vivir, pero no surgir”, tal como lo consigna el Informe de Desarrollo Humano Rural del año 2008. En los territorios agrarios, muchos campesinos viven afectados por malas condiciones económicas, el bajo precio en el que comercializan su producción, la precariedad de las condiciones laborales, la desorganización social y comunitaria, conflictos de tenencia de tierra y la destrucción y degradación de los recursos naturales y el deterioro ambiental. Estos factores son los que explican que en muchos países la producción agrícola viva malos días, aumentando los problemas de dependencia y de seguridad alimentaria.

Son innegables los efectos que vivieron los campos producto de las reformas agrarias impulsadas, y los procesos de modernización que corrían en paralelo a estas reformas, donde la producción agroindustrial ha llegado a ser la segunda actividad más importante en países como Chile, luego de la minera, dando cuenta de la relevancia que el sector productivo agroexportador ha ido adquiriendo en el proceso de crecimiento, transformándose en un puntal en lo que concierne a la inserción de los países de América Latina a los mercados globales. De manera paralela a esta situación, surgen nuevas problemáticas sociales, políticas, económicas y ambientales, lo cual denota una modernización desbalanceada que replica en los territorios agrarios los problemas del actual modelo de desarrollo neoliberal, asociados a una alta desigualdad, una precariedad laboral, a la concentración económica y los impactos que se han generado en el medio ambiente.

Lo anterior plantea nuevos desafíos para las ciencias sociales, invitándonos a repensar y reposicionar las problemáticas de la ruralidad, del modelo agrario y las nuevas configuraciones territoriales suscitadas a partir de la consolidación del proceso de modernización neoliberal, donde el actor tradicional de los espacios rurales se transforma, resignificando el rol del Estado y la transformación del modelo de acumulación, asociado a la nueva matriz socio política que emerge dentro de este contexto. Esto último tiene una directa incidencia en el papel que juegan los sectores rurales y agrarios en el actual contexto, lo cual nos invita a pensar también en la posibilidad que tienen los actores sociales, económicos y políticos de estos sectores de incidir en la construcción de un proyecto de desarrollo orientado a contrarrestar las nuevas exclusiones en estos espacios sociales.

En este marco, el número 47 de la revista POLIS, Revista Latinoamericana, convocóa investigadores(as) a escribir sobre las lecciones derivadas de los procesos de reforma agraria llevados a cabo en América Latina y especialmente en Chile a sus 50 años. Fundamentalmente pensando en las transformaciones que los territorios y sus actores han vivido producto de estos procesos.

A partir de aquello la sección “lente de aproximación” entrega una mirada retrospectiva acerca de lo que se ganó y lo que se perdió en los 
territorios agrarios rurales de América Latina, a cincuenta años de la implementación de la reforma agraria, entregando una diversidad de miradas y diferentes énfasis sobre la relevancia que han ido adquiriendo los territorios agrarios, la ruralidad y las necesidades de las cuales debemos hacernos cargo para enfrentar los desafíos de este sector en el nuevo escenario agrario global.

Esta sección se abre con el artículo Reforma agraria y movilización campesina en Chile (1967 - 1973) y Perú (1969 - 1976) de Octavio Avendaño, quien nos propone un análisis comparado de las reformas agrarias de Chile y de Perú. Por medio de la recopilación de antecedentes socio históricos este autor da cuenta de dos contextos opuestos de implementación, pero que obtuvieron similares resultados.A partir de los alcances del análisis comparativo este autor identifica los prinicipales tópicos donde ambas experiencias confluyeron, las cuales pueden sintetizarse en la relevancia de las propiedades colectivas; el rol central del Estado en la transferencia de recursos; la centralidad del control de los recursos natuales (tierra y agua); y, la creación de instituciones especializadas para conducir este proceso. Cabe señalar que al revisar las conclusiones a las que llega este autor, muchas de las ganancias socio productivas alcanzadas durante la reforma agraria fueron revertidasa partir de la instalación del modelo neoliberal, requiriendo hoyuna revisita a temáticas que fueron parte de los requerimientos y reividicaciones de los territorios agrarios hace más de medio siglo.

Por su parte, Tamara Carrasco, con su articulo Cambio generacional y radicalización campesina. Evolución del proceso de Reforma Agraria en Paine (1967 - 1973), ofrece una detallada revisión historiográfica del proceso de sindicalización campesina, en la Comuna de Paine -Chile, durante el proceso de reforma agraria. Su texto se enfoca en analizar las dinámicas internas y socio políticas, abordarndo las tensiones a las que se vío expuesto el movimiento sindical campesino,mediatizado por la tensión permanente con el sector patronal-latifundista; pugna que terminó determinando la forma en que se resolvió la deconstrucción del orden hacendal en la comuna y la emergencia de una nueva generación de líderes campesinos que, tras el golpe de Estado del 11 de septiembre de 1973, fueron perseguidos y desarticulados. Dentro de este trabajo se destaca la relevancia de mostrar los acontecimientos sucedidos en este territorio como un modo de poder recordar las implicancias que tuvo la Reforma Agraria en la zona central de Chile, y del mismo modo, generar estrategias para integrar en la memoria colectiva a los actores del proceso y sus historias.

En el artículo ‘Una verdadera revolución agraria’con y desde la Matría. Diana Gutiérrez entrega una aproximaciónhistórica de la experiencia de la reforma agraria en el sureste mexicano, donde precisamente la reforma quedó inconclusa y en deuda con campesinos/as y pueblos originarios.Esta autora plantea un análisis desde la voz de las mujeres en un esfuerzo de despatriarcalizar el relato, y de poner de manifiesto la invisibilización de las identidades rurales e indígenas. Junto con lo anterior pone en contexto al 
Movimiento Zapatista, el cual intenta luchar contra la política enajenante del Estado Mexicano a través de su propuesta de ley agraria revolucionaria, la cual propone incluir el sentido histórico que ha tenido la lucha defendiendo las relaciones con la tierra en tanto que Madre, pasando de la defensa y relación con la Patria a la Matría como aquella tierra que protege y da vida.

El trabajo de Jorge Olea Latifundio y territorio: reflexiones en torno a la reforma agraria en Colchagua, 1960 - 1973, plantea desde la perspectiva historiográficala importancia de revisar el lugar que tuvo para la reformanagraria la desaparición del latifundio, realizando una reflexión desde el territorio y el conflicto de la apropiación hegemónica de los recursos naturales. A partir de lo anterior este autor propone una distinción entre hacienda y latifundio. Asimismo, invita a discutir sobre la actualidad del latifundio, sosteniendo que el proceso de Reforma Agraria habría sido solo el fin de la hacienda mas no el de la gran propiedad.

Desde una perspectiva actual el trabajo La cuestión agraria cubana aciertos y desaciertos en el período de 1975 - 2013: la necesidad de una tercera reforma agraria de Tatiana y Lázaro Recompensa abordar lasprincipales transformacionesagroproductivas introducidas en la economía cubana en el periodo de 1975 a 2013, con un énfasis preciso en la denominada Tercera Reforma Agraria puesta en marcha a partir de 1993; la que implicó el tránsito hacia un nuevo modelo agrario cuyo objetivo principal fue resolver un problema emergente como es el de la soberanía alimentaria. De esta forma estos autores analizan y explican éste nuevo modelo de reforma agraria identificando sus principales aciertos y desaciertos en el contexto cubano.

Vanderlei Vazelesk presenta su texto De la lucha por la tierra a la protección de la Pachamama: los caminos de la Confederación Campesina del Perú (1947 - 2016), el cual centra la discusión en la problematizacióndel rol que ha jugado la Confederación Campesina del Perú (CCP), como entidad representativa de los campesinos de este país desde hace siete décadas. Desde el punto de vista teórico, el artículo ahonda en la noción de construcción de clase durante los procesos históricos. Desde el punto de vista empírico, se muestran los resultados de una investigación más amplia que reflexiona sobre la reforma agraria peruana, que se desencadenó a partir de 1969. Enfatizado en sus alcances la relevancia que tuvo la movilización de los campesinos peruanos a lo largo de las diversas coyunturas que ha atravesado el país.

Cerrando esta sección, se presenta el artículode Marcel Thezá, Daniel Flores y Daniella Gac, Reforma agraria en Chile, ¿Palimpsesto de otra ruralidad? Reflexiones y propuestas, el cual realiza una aproximación al proceso de reforma agraria chilena a partir de la revisión de lasdimensiones: productiva, social y cultural, inscritas dentro de los lineamientos que se proponía la transformación de los campos chilenos. Este artículo discute acerca de la relevancia que tuvo para la reforma agraria en Chile la reconfirguración de las relaciones de poder, surgiendo a partir de lo anterior 
la hipótesis de que a cincuenta años de esta reforma lo que se reconoce en los campos chilenos es una lógica de "palimpsesto" debido a que las fronteras de cambio histórico son difusas y no permiten definir las actuales realidades que tensionan los territorios agrarios en la actualidad. 